\title{
The Use of VR for Creating Therapeutic Environ- ments for the Health and Wellbeing of Military Personnel, Their Families and Their Communities
}

\author{
Jacqueline McIntosh $^{1}$, Maria Rodgers ${ }^{1}$, Bruno Marques ${ }^{1}$, Alysha Gibbard ${ }^{1}$ \\ ${ }^{1}$ Victoria University of Wellington, School of Architecture, Wellington/New Zealand · \\ bruno.marques@vuw.ac.nz
}

\begin{abstract}
A military lifestyle can have profound impacts on an individual's health and wellbeing. Increasingly, new technologies such as the creation of Virtual Reality (VR) are being explored as bridging mechanisms to provide 'space' and to aid with other therapies. The overarching research programme investigates the therapeutic and social qualities of landscape and how these can be translated into an immersive virtual environment. There is a specific focus regarding immersive VR environments and how these could be used as a tool to promote positive health, wellbeing, and social connection within the New Zealand Defence Force (NZDF).
\end{abstract}

Keywords: Virtual Reality, Therapeutic Landscapes, Landscape Architecture, Military

\section{Introduction}

The New Zealand Defence Force (NZDF) has a major role in contributing to New Zealand's defence, security, and wellbeing. The community tasked with taking on these responsibilities contains regular force members, reservists, veterans, civilians and by extension, the families of these personnel. The effects of this military lifestyle on an individual and their family are profound and well documented (MCBRIDE 2017). Typical stressors such as childcare, elder care, and financial concerns for example, all need to be dealt with by personnel and their families. In addition, unique stresses such as continual relocation, prolonged separation and repeated exposure to traumatic events (DRUMMET, COLEMAN et al. 2003) also affect their health and wellbeing. The need for temporary reprieve or relief is often unmet, and can often lead to poor coping strategies with potentially damaging consequences (IREMONGER, AtAlaG et al. 2015, DE TERTE 2017).

Increasingly, Virtual Reality (VR) environments are being explored as bridging mechanisms to provide 'space' and to aid with other therapies. While much research has been published with respect to the success of using VR environments in treating Post-traumatic Stress Disorder (PTSD) in soldiers or phobias in civilians, relatively little has been published with respect to the use of VR for ongoing health and wellbeing. Within the health and wellbeing literature, the relationship between healthy wellbeing and outdoor experience is well documented. In particular, research finds that immersion in nature can offer mental and physical benefits ultimately contributing to a state of healthy wellbeing (HUMBERSTONE 2015).

This research programme explores opportunities for ongoing therapeutic and social experiences in virtual landscapes and examines the design attributes required to create a successfully immersive VR environment that can contribute to good health and wellbeing. In particular, this research focuses on the attributes and landscapes that contribute to developing therapeutic and social design qualities in order to create a VR platform that fosters and promotes

Journal of Digital Landscape Architecture, 4-2019, pp. 185-194. (C) Wichmann Verlag, VDE VERLAG GMBH Berlin · Offenbach. ISBN 978-3-87907-663-5, ISSN 2367-4253, e-ISSN 2511-624X, doi:10.14627/537663020. 
ongoing health, wellbeing, and social connection for New Zealand Defence Force community members.

\section{Literature Review}

\subsection{Approach}

This research examines the body of literature that addresses military lifestyles, virtual reality, immersive simulation, landscape, and health and wellbeing. It groups the findings together into two streams: health and wellbeing within VR applications; and health and wellbeing in the designed environment. A thematic analysis is undertaken in order to identify and understand; current uses of VR to promote health and wellbeing; the successful attributes of these; therapeutic attributes of real-world landscapes, and which of these are suitable to be translated into a VR environment.

\subsection{Health, Wellbeing and Virtual Reality}

The use of VR as a tool within the health and wellbeing sector is an emerging area of research. Therapeutic uses of VR include creating interactive systems that help to reduce anxiety or stress; reduce phobias and assist in the development of skills or training for those with disabilities. However, while much has been published with respect to the use of VR for treating PTSD in soldiers (REGER, HoLlOWAY et al. 2011) or chronic fears in civilians (GARCIAPALACIOS, HOFFMAN et al. 2001), relatively little has been published with respect to the needs for ongoing health and wellbeing, and specifically in regards to ongoing therapeutic and social benefits.

When used in very specific applications, VR environments have been proven to provide an immersive experience capable of eliciting real emotion (BADIA 2018). The most explored application of VR in healthcare is as a form of exposure therapy, where VR is used to replicate an environment which contains a scenario or object that is associated with fear or trauma by the individual seeking treatment. Outside of New Zealand, this type of VR environment has been used extensively within a military context as a health and wellbeing tool with a strong precedent in the United States of America (RIZZO, PARSONS et al. 2011, RIZZO, LANGE et al. 2011). VR is used for both specific training scenarios and treatment-based therapies of clinical conditions. Though studies and therapies of this nature are important in regards to highlighting specific health benefits of VR, their singular clinical focus means they do not address the wider psychological and social factors of VR environments that can have a major impact on an individual's ongoing health and wellbeing.

Across these studies it was noted that VR appealed to individuals seeking treatment, as it provided some psychological distance from their source of trauma while still effectively treating the feelings experienced from that same trauma. The novelty of VR environments appears to facilitate a greater rate of engagement in individuals seeking care because of this (GARCIAPALACIOS, HOFFMAN et al. 2001). In a less clinically-specific scenario, the sparse literature which covers VR environments in regards to general wellbeing, also supports the notion that VR is able to elicit genuine emotion within individuals. BADIA (2018) found that a simple designed maze in VR was capable of eliciting targeted emotions within users when using specific audio and visual stimuli to create a supplementary atmosphere. 
It is also worthwhile investigating the qualities of a virtual landscape that cause individuals to become immersed. BULU (2012) studied the relationship of an individual's 'presence' in a VR environment to the satisfaction of an immersive experience. Three dimensions of presence were related and were identified as indicators for predicting user satisfaction in an immersive environment. 'Physical presence' involves creating a sense of 'realness' within the environment, with an emphasis on representing a three-dimensional experience through aspects such as texture, light, sound, and motion. 'Social presence' refers to the 'face to face' engagement with other users, through written, oral or other (e. g. facial or avatar expression) communication cues. 'Co-presence' is similar to social presence, however 'co-presence' refers to the psychological aspects of interaction - i. e. 'having a sense of perceiving others and having them perceive you' and actively being a part of a group (BULU 2012).

\subsection{Environments and the Promotion of Health and Wellbeing}

The relationship between healthy wellbeing and outdoor experiences is well documented. Previous research finds that immersion in nature can offer mental and physical benefits that ultimately contribute to a state of healthy wellbeing (LEE, PARK et al. 2009, SODERLUND \& NEWMAN 2015, KERSHAW, MCINTOSH et al. 2017). Being immersed within nature affords an emotional experience that is unique for each individual, but is nearly always a positive one.

In New Zealand, the landscape is considered to be an important part of the national identity. Most New Zealanders regularly connect to the landscape by interacting and immersing themselves through activities such as hiking or tramping, camping and boating in a wilderness or semi-wilderness environment (MCKONE, MCINTOSH et al. 2016). In particular, indigenous Māori connect to landscape deeply through cultural practice and beliefs that originate from before European colonisation (MARQUES, MCINTOSH et al. 2018). For Māori, the landscape is a central concept around which the four pillars of health: taha tinana-physical wellbeing; taha hinengaro - mental and emotional wellbeing, taha whanau - social wellbeing; and taha wairua - spiritual wellbeing, are intrinsically connected and support each other (DURIE 1994). All four dimensions are necessary for strength and symmetry and must be considered together.

The relationship between Māori and the landscape also extends into a deeper territory of cultural identity, which encompasses not only landscape as a whole but also to the individual flora and fauna that make it up. This is especially true of endemic New Zealand flora. The traditional Māori practice of Rongoā (traditional herbal medicine) utilises medicinal properties of plants, and involves spiritual methods of healing together to create a well-rounded healing environment which utilises and treats all four pillars of health (MARK \& LYONS 2010). Symbolic representations of New Zealand's native plants are also commonly displayed as symbols of the nation's identity.

Indigenous flora and fauna is also a component of cultural identity, not just for Māori, but also for all New Zealanders: national sports teams wear the Silver Fern. A koru, the Māori art design depicting an unfurling fern frond, is the logo of New Zealand's national airline. (DANA \& HIPANGO JR 2011)

In this respect, landscape environments and particularly New Zealand landscapes, can provide a solid foundation from which to investigate immersive representations of landscape. This is particularly relevant for personnel who are either deployed into hostile, harsh, combat environments; experiencing difficulty connecting with family members; or who are simply 
seeking some respite while working through difficult situations. It is pertinent to understand what therapeutic and social design qualities of landscape can be translated into a virtual environment. Obviously, the full environmental benefits of vegetation and landscape cannot be completely replicated in a virtual environment, however the socio-psychological benefits can possibly be.

AвBOTT (2008) deconstructs how we experience a physical landscape into two fields; visual engagement and haptic engagement. The idea is that anyone can "gain a visual appreciation of the surrounding endemic flora" however without actually being engaged with the site, it is "difficult to assert that the track is an integrated part of the ecologically indigenous landscape" (АВBOTт 2008). This concept is supported by other recent studies and literature which find that both passive and active involvement with an environment can be cathartic - providing a sense of pleasure, satisfaction and healing (MILLIGAN, GATRELL et al. 2004). Visual interactions, such as those with nature imagery and symbolic representations, have been studied extensively and are recognised for their ability to elicit emotion and distract potentially 'captive' populations (TAYLOR 2006). Similarly, research investigating community-based landscapes such as community gardens and parks that provide a range of both social and individual as well as active and passive activities, create an environment which nurtures a sense of healthier wellbeing for a range of reasons (WINTERBOTTOM \& WAGENFELD 2015).

\section{Modelling of Therapeutic Virtual Environments}

The modelling of therapeutic VR environments was explored first through the application of readily available technologies. These were then used to model the New Zealand landscape environment and preliminarily tested on defence personnel.

\subsection{Technologies}

The virtual landscape was generated using Unreal Engine 4.21 which was developed by Epic Games (https://www.unrealengine.com/en-US/what-is-unreal-engine-4). As there were little to no available or realistic 3D modelled New Zealand native trees or plants, they had to be developed and modelled in 3DS Max 2018 (https://www.autodesk.co.nz/products/3dsmax/overview). These were then exported into Unreal Engine 4.21 to populate the landscape. Revit 2018 (https://www.autodesk.com/products/revit/architecture) was used to model architectural elements of the environment and then exported into Unreal Engine 4.21 via 3DS Max due to incompatible file types between Revit and Unreal Engine. For this study, an HTC Vive (https://www.vive.com/nz/product/) head mounted display unit with 110 degrees field of view and tracking area of $5 \times 5 \mathrm{~m}$ was used as the immersive presentation device, along with HTC Vive wireless controllers to allow movement within the environment. The HTC Vive display unit was connected using a cable to a PC, however the HTC Vive display unit and wireless motion controllers are tracked via lasers emitted from two base stations positioned around the work area. Using SteamVR tracking to run the experiment, (https://partner.steamgames.com/vrlicensing), the tracked motion controllers from these base stations were automatically interpreted into the VR environment and the representational avatar of the hands were displayed in real-time for the VR user. 


\subsection{Therapeutic Virtual Reality Environment: "New Zealand Bush"}

Through the literature review, three main criteria were found to be important for a therapeutic environment: authenticity, extensive and immersive multi-sensory experience and social connection. Native New Zealand landscapes are distinctive and easily recognisable by the people of New Zealand. A multi-sensory engagement with a landscape can establish a closer relationship with the user of that landscape, in both virtual and real environments.
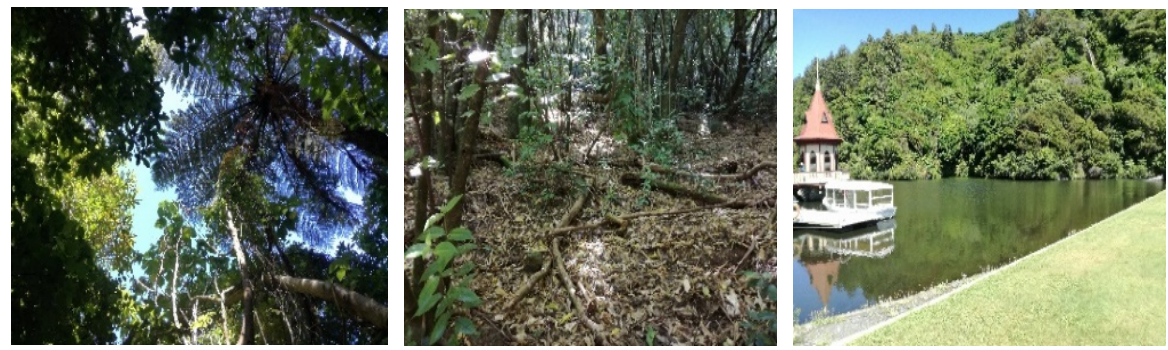

Fig. 1: Images of native New Zealand bush as precedents and modelling references
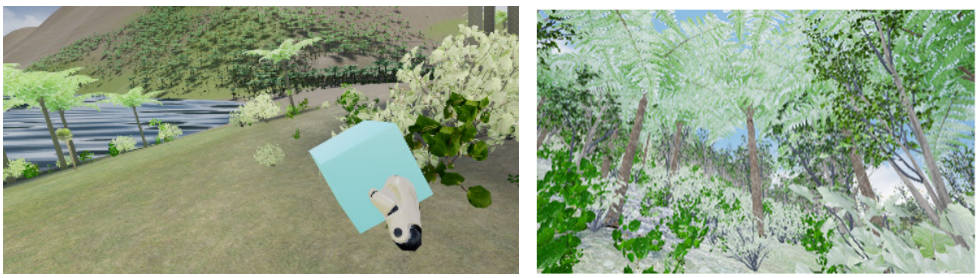

Fig. 2: Screen captures of the developed VR environment

The developed VR environment simulates a native New Zealand bush environment, populated with common endemic New Zealand plants and trees, both culturally relevant to Māori culture and those of European descent (Figures 1 and 2). This landscape scene was developed specifically to establish a sense of familiarity for the user, with the intention of contributing to a sense of 'physical presence' through familiar textures, materials, light patterns, terrain, vegetation, and sounds. The natural New Zealand bush environment is home largely to native fauna such as birds, tuatara (lizards) and insects; with larger introduced animals such as deer, wild boar, feral goats and possums. Integrated into the VR environment are sound recordings of native New Zealand bird calls, alongside other sounds associated with a bush environment. These are embedded within the VR landscape on "Audio Components", which are triggered due to proximity, and similarly, the audio volume differs dependant on the proximity of the user to the centre of the audio components effective area. Within this VR environment, no visual models or simulations of animals are currently incorporated - this is due to the fact that large animals are not commonly found in this environment. Meaningful interaction opportunities with simulations of such animals are difficult to be incorporated, and while animated animals could be incorporated, this requires extensive knowledge of the Unreal Engine, beyond the capabilities of the authors. 
Inanimate objects such as sticks, balls and some plants have been modelled as interactive models that users can pick up, move, throw, stack, and place. Haptic feedback [vibrations] from the HTC Vive controllers contribute to the illusion of grasping objects within the VR environment. These interactive features have been incorporated so that users can have an aspect of control over the environment, much like in a real landscape. The interaction contributes to a complete multi-sensory experience where the environment is not only stimulating users visually, but audibly and physically as well. The ability to cultivate the landscape and control the environment by users also allows the user to alter the environment into one in which they feel a deeper personal connection, which plays into the therapeutic values of Māori and their relationship with the land, wherein only a well-rounded landscape environment with ties to all four pillars of health can provide a space to heal.

Motion is controlled through two different methods. The viewer can either 'teleport' by pressing and releasing the motion pad on the HTC Vive controllers, or they can actively walk themselves around the immediate environment, with the movement being tracked and displayed in real-time on their display.

\subsection{Testing}

Preliminary testing of the environment was conducted with semi-structured interviews and observations taking place with a small number of defence personnel as well as other postgraduate researchers, during and after interacting with the developed VR environment. The interviews were conducted with a focus on identifying; satisfaction with the overall immersive experience and its therapeutic value; satisfaction with individual features of the environment and their value in creating an immersive experience; and areas of interaction which were missing or could be developed further.

\section{Results}

The resulting VR environment is an immersive landscape in which users can explore freely, where natural sounds provide ambient noise, blocking any real-world sounds which might interfere with the illusion (Figure 3). Users can look around in all directions, pick up, throw, stack, or position objects in the environment such as sticks, blocks and balls. Landscape design features, such as sunlight and shadow, texture, colour, vegetation and density, were all incorporated into the environment to create a VR landscape which simulates the landscape in real life.

The modelled terrain and vegetation were recognised by participants as New Zealand natives, although the vegetation specifically was both praised and criticised. Based on comments while experiencing the VR, the level of detail in terms of materials and texture of materials was beyond most participants' expectations of what they thought could be achieved in VR. However, the overall form of the modelled vegetation, while recognisable, appeared awkward to participants from a distance, as they could not perceive the texture and detail of the vegetation in the VR environment, which is different to the real-life situation of perceiving a landscape and the associated vegetation. 


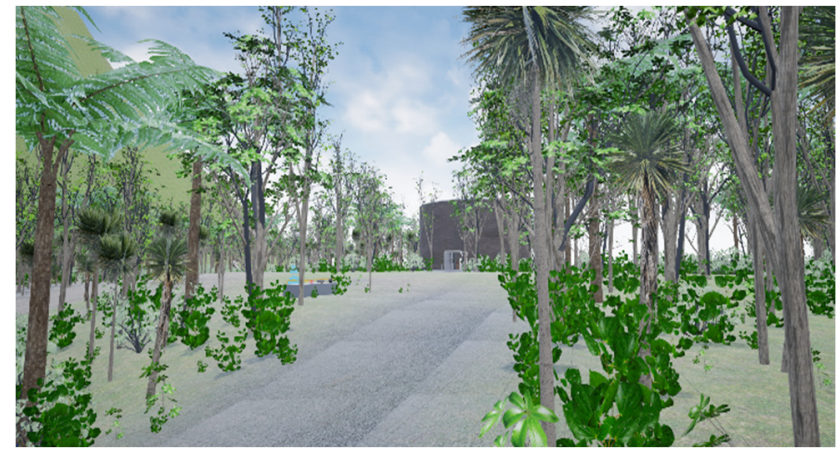

\section{Fig. 3:}

New Zealand bush VR simulation moment capture

Some of the bird calls were also recognised as familiar, however only some participants were able to recognise a specific species or that they were New Zealand natives. The ability to 'pick up' objects was rated highly and it was observed that this feature was a surprise to the participants, as it provided them the opportunity to actively engage with the VR environment, increasing their social and physical presence, and simultaneously enhancing the therapeutic values of that environment. This observation was solidified by the need to prompt users to attempt to pick objects up in order to receive feedback on this feature.

It was observed that all participants relied on teleporting as the main method of movement around the environment, however during the interviews it was revealed that participants were reluctant to walk around in case they hit the computer desk, or walked the cable to the end of its tether. It was noted that participants did not mind the unnatural movement method of 'teleporting', however if trying to 'travel' to a part of the environment that was 'far away', the constant and repetitive flickering of the screen could be annoying and induced a sense of motion sickness. The ability to navigate freely around the VR environment without being restricted to a path was liked, although it was shown that the model needs to be thoroughly investigated for code glitches and modelling inaccuracies before participants use it, as many participants became curious as to the limitations of the environment, and attempted to see if they could walk through trees, or walk on water.

\section{$5 \quad$ Discussion and Limitations}

The level of immersion into the virtual environment depends on the illusion of reality to the senses of a participant. (HAYEK, WALTISBERG et al. 2016)

An immersive VR experience relies on the ability to elicit emotion within users through the fabrication of 'unreal' environments and the associated stimuli. Previous research has found that utilising stimuli that create a multi-sensory environment such as static visual models, audio, interactive objects, and haptic feedback contribute to a heightened level of immersion within a VR environment. However, previous research fails to directly address how specific design features can contribute to and create an immersive VR environment with a desired experiential and emotional outcome.

Through the modelling process, we found that the addition of a desired emotional experience and target user group helped to design and select stimulus features within which to immerse 
users. The design features were tailored to create a therapeutic experience which would resonate with the target users and required particular focus and attention to detail in order to achieve this desired effect. The focus then was to investigate how easily VR features which elicit emotion and contribute to an immersive environment can be adapted to create specific experiences.

While 3D models exist for many plant types, there are no available models for native New Zealand plants, therefore these had to be modelled. Aspects such as trees, shrubs and plants, are very complicated and time consuming to model realistically. There is the additional problem of retaining a visual quality and realism of these models when complete, while also ensuring they are simple enough for Unreal Engine to render in real-time without resulting in very slow frame rates. Subsequently, once these models have been completed, they are used to populate the VR environment and create a forest experience, with different densities, plant clusters, and growth stages. Unreal Engine has the capacity to alter aspects such as density, size, and rotation of an individual model as well as the ability to cluster different types of plants together. However, while this mitigates a visual 'cloned' appearance of the same plant in the VR environment to a certain degree, there is still a very prominent 'repetitive' aesthetic quality which does not align with the visual qualities of a real New Zealand bush-scape. To achieve a realistic bush-scape, plants with different growth stages and a range of growth patterns all need to be modelled individually - which in turn contributes to the initial problem of a complicated and lengthy modelling process.

Conversely, other landscape features which contribute to multi-sensory experiences can be readily achieved within a VR landscape with little effort necessary. This is especially true in Unreal Engine. Atmospheric qualities such as wind and audio have been simplified into pieces of programme which can be changed, adjusted or added with simply a few clicks and drags of a mouse. Incorporating opportunities within the landscape for active and haptic engagement, such as the throwing/placing of objects like sticks or balls, or multiple users, can be achieved as well, but requires more intimate knowledge of Unreal Engine to be able to incorporate these effectively and realistically. The responses provided by participants showed that these atmospheric qualities added realism to the VR experience, and interactive objects like the balls were observed to greatly uplift the overall experience and connection with the environment.

However, based on the participants' feedback, visual aspects of the VR landscape, such as trees, plants, and terrain, lacked the same levels of realism achieved by the multi-sensory design features. Another feature which drew commentary was the methods of navigating through the VR environment. For shorter periods of travel, the two methods of walking and teleporting were satisfactory for the users. Although when wanting to travel further into the landscape, teleporting became the favoured option of navigation as it was quicker, however the constant flickering transition could become overwhelming. Also, while users could not walk through dense objects such as tree trunks, the ability to 'walk' through other less dense bushes and scrub was labelled as 'off-putting'. Within a real landscape, walking through low density scrub is possible although the sensation of branches and leaves brushing against one's arms and legs that would be felt in real life, cannot be replicated within VR - speculatively, this could be the cause as to why some participants found objectionable walking through the bush with leaves in front of their eyes. 


\section{Conclusions}

This research focused on promoting health, wellbeing and social connection within the NZDF, using VR to provide respite from the harsh and stressful conditions of a military lifestyle. Specifically, it looked to create an immersive experience in the unique New Zealand bush through identification and implementation of landscape design attributes using VR. It found that many design features of landscape with therapeutic tendencies can be simulated in VR, and for the most part these can effectively create the intended atmosphere. This was particularly true for features which serve functions other than that those of just being seen or observed. Features which are predominantly visual aspects of VR, however tend to detract from the overall experience. While the study was highly exploratory in nature, the results demonstrated that VR landscapes have the capacity to foster health, wellbeing and social connection in a manner similar to real landscapes. However, methods of modelling and representing 3-dimensional vegetation in VR needs to be investigated further to enhance a 'realistic' experience. Further development and more extensive testing are necessary to validate these findings.

\section{References}

Aввотт, M. R. (2008), Designing wilderness as a phenomenological landscape: designdirected research within the context of the New Zealand conservation estate, Lincoln University.

Badia, S., Chirico, A., CAmeirao, M. \& Triberti, S. (2018), Towards EmotionallyAdaptive Virtual Reality for Mental Health Applications. IEEE Journal of Biomedical and Health Informatics, 11.

BuLU, S. (2012), Place presence, social presence, co-presence, and satisfaction in virtual worlds. Computers \& Education, 58 (1), 154-161.

DANA, L.-P. \& HIPANGO JR, W. (2011), Planting seeds of enterprise: Understanding Māori perspectives on the economic application of flora and fauna in Aotearoa (New Zealand). Journal of Enterprising Communities: People and Places in the Global Economy, 5 (3), 199-211.

DE TERTE, I. (2017), The straw that broke the camel's back: A model of psychological resilience to use with military personnel. Global Views on Military Stress and Resilience, 127-137. Winnipeg, Canada.

Drummet, A., Coleman, M. \& Cable, S. (2003), Military families under stress: Implications for family life education. Family relations, 52 (3), 279-287.

DuRIE, M. (1994), Mason Durie's Whaiora: Māori Health Development. Oxford University Press, Auckland, New Zealand.

Garcia-Palacios, A., Hoffman, H. G., Kwong See, S., Tsai, A. \& Botella, C. (2001), Redefining therapeutic success with virtual reality exposure therapy. CyberPsychology \& Behavior, 4 (3), 341-348.

HayeK, U. W., Waltisberg, D., PhilipP, N. \& Grêt-Regamey, A. (2016), Exploring issues of immersive virtual landscapes for the support of participatory spatial planning support. Journal of Digital Landscape Architecture, 1-2016, 100-108.

Humberstone, B. (2015), Embodiment, nature and wellbeing. Experiencing the outdoors, 61-72. Springer. 
Iremonger, G. S., AtAlag, K., Johnston, B. J. \& CAMPBell, A. (2015), Epidemiology of medical discharge in the New Zealand defence force. Journal of Military and Veterans' Health, 23 (4), 82-91.

Lee, J., Park, B.-J., Tsunetsugu, Y., Kagawa, T. \& Miyazaki, Y. (2009), Restorative effects of viewing real forest landscapes, based on a comparison with urban landscapes. Scandinavian Journal of Forest Research, 24 (3), 227-234.

Kershaw, C., Mcintosh, J., Marques, B., Cornwall, J., Stoner, L. \& Wood, P. (2017), A potential role for outdoor, interactive spaces as a healthcare intervention for older persons. Perspectives in Public Health, 137 (4), 212-213.

MARK, G. T. \& LYONS, A. C. (2010), Māori healers' views on wellbeing: The importance of mind, body, spirit, family and land. Social Science \& Medicine, 70 (11), 1756-1764.

MARQues, B., GRABASCH, G. \& MCINTOSH, J. (2018), Fostering landscape identity through participatory design with indigenous cultures of Australia and Aotearoa/New Zealand. Space and Culture, 1206331218783939.

MCBRIDE, D. (2017), The psychological and physical health and wellbeing of New Zealand contemporary veterans.

McKone, M., McIntosh, J. \& MArques, B. (2016), Enabling Wilderness: Creating the opportunity for disabled tramping within New Zealand's national parks. Peer Reviewed Book of Proceedings, 190.

Milligan, C., GAtrell, A. \& Bingley, A. (2004), 'Cultivating health': therapeutic landscapes and older people in northern England. Social science \& medicine, 58 (9), 17811793.

Reger, G. M., Holloway, K. M., Candy, C., Rothbaum, B. O., Difede, J., Rizzo, A. A. \& GAHM, G. A. (2011), Effectiveness of virtual reality exposure therapy for active duty soldiers in a military mental health clinic. Journal of traumatic stress, 24 (1), 93-96.

Rizzo, A., Parsons, T. D., Lange, B., Kenny, P., Buckwalter, J. G., Rothbaum, B., Difede, J., Frazier, J., NewMAN, B. \& Williams, J. (2011), Virtual reality goes to war: A brief review of the future of military behavioral healthcare. Journal of clinical psychology in medical settings, 18 (2), 176-187.

Rizzo, A. A., Lange, B., Buckwalter, J. G., Forbell, E., Kim, J., Sagae, K., Williams, J., Rothbaum, B. O., Difede, J. \&REGER, G. (2011), An intelligent virtual human system for providing healthcare information and support, Madigan Army Medical Center Tacoma WA, 503-509.

SODERLund, J. \& NEWMAN, P. (2015), Biophilic architecture: a review of the rationale and outcomes. AIMS Environmental Science, 2 (4), 950-969.

TAYLOR, R. P. (2006), Reduction of physiological stress using fractal art and architecture. Leonardo, 39 (3), 245-251.

Winterbottom, D. \& WAGEnFeld, A. (2015), Gardens for Veterans. Therapeutic gardens: design for healing spaces, 183-186. Portland, Oregon, Timber Press. 